\title{
IMPACT THE TEMPERATURE OF BANGLADESH: AN APPLICATION OF MARKOV MODEL
}

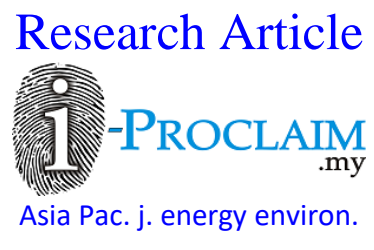

\author{
Janardan Mahanta ${ }^{1}$, Syed Tanjim Hossain ${ }^{2}$, Imtiaz Reza ${ }^{3}$ \\ ${ }^{1}$ Assistant Professor, Department of Statistics, University of Chittagong, Chittagong, BANGLADESH \\ ${ }^{2,3}$ Research Student, Department of Statistics, University of Chittagong, Chittagong, BANGLADESH \\ *Email for Correspondence: johnstat@cu.ac.bd
}

Manuscript Received: 25 June 2019

Revised: 08 November 2019

$-$

Accepted: 03 January 2020

Abstract

Markov chain model has been used to analyze the temperature of Bangladesh. Different order Markov chain model has constructed and their significance has been tested. Using Cramer's $V^{2}$, strength the association of temperature with the order of Markov chain has been measured. Stationary probability has been calculated, and there have been employed whether the temperature is stationary or not.

Key words

Temperature, Bangladesh, Markov Model

This article is is licensed under a Creative Commons Attribution-NonCommercial 4.0 International License.

Attribution-Non Commercial (CC BY-NC) license lets others remix, tweak, and build upon work non-commercially, and although the new works must also

acknowledge \& be non-commercial.

\section{INTRODUCTION}

Global warming is the big issue; we are facing today as the greatest challenge. In fact, global warming is the continuous and steady process of increasing the temperature of the earth surface. Climate change and its impacts are the current burning issue in the world. It is now unequivocally established that climate change is the reality, and the adversities of climate transformations pose of the greatest challenges facing humanity today (IUCN, 2011). The recent finding of the fourth assessment report of the world's scientific community, represented by the InterGovernmental Panel on Climate Change (IPCC). Various human activities are making the world hot to hotter; the ultimate result is global warming i.e. climate change. According to an ongoing temperature analysis conducted by the scientist at NASA'S, the average global temperature on Earth has increased by $0.8^{\circ} \mathrm{c}$ since 1880 . Two third of warming has occurred since 1975 , at a rate of $0.15^{\circ}-0.20^{\circ} \mathrm{c}$ per decade. Modeling studies by Haque et al. (1992) indicated that the average increase in temperature would be $1.3^{\circ} \mathrm{C}$ and $2.6^{\circ} \mathrm{C}$ for the projected years of 2030 and 2075 respectively. Now its challenges are multi-dimensional, and multi-sectorial has immediate as well as long-term effect. It is a huge task to assess the changing pattern of the climatic system since the changing state of the climate is the result of many factors locally and globally. But the most common factors through those the change of climatic system is being assessed are temperature, rainfall, ground and sea water level, etc.

Agriculture is the most vulnerable sector as it productivity depends on climate factor like temperature, rainfall, light intensity, radiation and sunshine duration, which is predicted to be erratic. A study found that $10^{\circ} \mathrm{C}$ increase in maximum temperature at vegetative, reproductive and ripening stages there was a decrease in Aman rice production by $2.94,53.06$ and 17.28 tons respectively. With the change in temperature (by $20^{\circ} \mathrm{C}$ and $40^{\circ} \mathrm{C}$ ), the prospect of growing wheat and potato would be severely impaired. Production loss may exceed $60 \%$ of the achievable yields (Karim, 1993). Higher temperature has the negative effect on soil organic matter also.

Temperature is an important component of atmosphere, and the effect of temperature increase is extreme in the natural system. In this study a modest attempt to analysis temperature data of Chittagong and Dhaka station, Bangladesh by employing statistical techniques. Mahanta et al. (2016) employed the impact of temperature in Bangladesh based on Markov analysis. This paper has been made an effort to analyze the temperature of Bangladesh using the latest techniques based on Markov chain developed by, such as, Gabriel and Neumann (1962) and Stern and Coe (1984). The main objective of this paper is to analyze the patterns of temperature occurrences for Bangladesh and to show the order of Markov model which provides a good fit. 


\section{MetHodology}

This article has been used temperature data taken from "Bangladesh Metrological Department" Climate Division, Agargaon in Dhaka. Two stations such as Dhaka in period 2003-2013 and Chittagong in 2008-2013 have been taken.

\section{Chittagong Station}

Chittagong is the second largest metropolis in Bangladesh. Situated in the Bay of Bengal, Chittagong has historically been an important center of commerce due to its geo-strategic location and is regarded as the commercial capital of the country. The city is well known for its scenic beauty and the unique combination of hills to the north, flat land bounded by the Karnaphuli River to the southeast, the Halda River Valley to the northeast and the Bay of Bengal to the west. Chittagong lies at $22^{\circ} 22^{\prime} 0^{\prime \prime} \mathrm{N}, 91^{\circ} 48^{\prime} 0^{\prime \prime} \mathrm{E}$. The average temperature for the year in Chittagong is $78.6^{\circ} \mathrm{F}$ $\left(25.9^{\circ} \mathrm{C}\right)$. The warmest month, on average, is May with an average temperature of $83.3^{\circ} \mathrm{F}\left(28.5^{\circ} \mathrm{C}\right)$. The coolest month on average is January, with an average temperature of $67.9^{\circ} \mathrm{F}\left(19.9^{\circ} \mathrm{C}\right)$. Chittagong has experienced the highest temperature in last 54 years was $39.5^{\circ}$ in May, 2001. The lowest temperature in the city's history was recorded at $7.7^{\circ}$ C in January, 1992.

\section{Dhaka Station}

Dhaka is the capital city of Bangladesh and the principal city of Dhaka District located on the banks of the Buriganga River. The population is over 18 million in the in greater Dhaka area, making its largest city in Bangladesh and one of the most populations in the world. Dhaka has experienced the highest temperature in last 54 years on 24 April 2014 as the mercury reached at 40.2 degree Celsius. Earlier on April 30, 1960, the capital had experienced the highest temperature as 42.3 degree Celsius, according to Bangladesh Meteorological Department. Dhaka experiences a hot, wet, and humid tropical climate. Under the KOPPEN climate classification, Dhaka has a tropical savanna climate. The city has a distinct monsoonal season, with an annual average temperature of $26^{\circ} \mathrm{C}\left(79^{\circ} \mathrm{F}\right)$ and monthly means varying between $19^{\circ} \mathrm{C}\left(66^{\circ} \mathrm{F}\right)$ in January and $29^{\circ} \mathrm{C}\left(84^{\circ} \mathrm{F}\right)$ in May. Approximately $87 \%$ of the annual average rainfall of 2,123 millimeters (83.6 inches) occurs between May and October.

The prompt development of computer and information technology makes the procedure of analyzing data easier. Now a day, none can thing to analyze data without a suitable computer program. To analyze the data quickly, easily and correctly has no alternate of the computer program. Microsoft Excel, SPSS, and R programming have been used in the article.

\section{MARKOV MODEL}

Consider a stochastic process $X(t)(t=1,2, \ldots \ldots)$ that takes on a finite number of states $k$. in general, the process $X(t)$ is in state $s=1,2, \ldots \ldots, k$ at the time $t=n$ if $X(n)=s$.

Let $\mathrm{s}(\mathrm{t})$ denote the observed state of the stochastic process at time $t$. For example, the initial state of the stochastic process is represented by $X(t=1)=s(t)$. In this application, the process $X(t)$ has three states, namely $X(t)=1$ if the observed day is low temperature, $X(t)=2$ if the observed day is medium temperature and $X(t)=3$ if the observed day is the high temperature. Temperature has been classified by Low $\left(<20^{\circ} \mathrm{C}\right)$, Medium $\left(20^{\circ} \mathrm{c}-30^{\circ} \mathrm{C}\right)$ and High $\left(>30^{\circ} \mathrm{C}\right)$. Furthermore, suppose that for all $t=1$, the Markov property holds, that is,

$P(X(t+1)=s t+1 \mid X(t)=s t, X(t-1)=s t-1, \ldots . ., X(2)=s 2, X(1)=s 1)$

$=P(X(t+1)=s t+1 \mid X(t)=s t)$

In words, this property states that the probability of being in state st +1 at time $t+1$ depends only on the current state st. As related to this example, observation of a significant tomorrow's temperature condition depends only on whether (or not) a significant temperature condition is observed today and not on earlier temperature condition. This model thus incorporates the dependence of tomorrow's temperature depends on today's observed temperature to inform the probability of observing a significant temperature tomorrow.

The three states transition probability matrix is given below.

$$
\begin{array}{clccc} 
& \multicolumn{4}{c}{\text { Next day }} \\
& & \mathbf{1} & \mathbf{2} & \mathbf{3} \\
\text { Current day } & \mathbf{1} & \mathbf{2} & {\left[\begin{array}{ccc}
p_{11} & p_{12} & p_{13} \\
p_{21} & p_{22} & p_{23} \\
p_{31} & p_{32} & p_{33}
\end{array}\right]}
\end{array}
$$


This chain dependent process is irreducible, since every state communicates to each other. With ergodic states $1,2,3$ the Markov chain $\left(X_{n}\right)$ is said to be of order $\mathrm{k}(\mathrm{k}=1,2,3,4 \ldots)$ for all $\mathrm{n}$, if and only if,

$p_{i j k}=\operatorname{prob}\left(X_{n}=k / X_{n-1}=j, X_{n-2}=i\right) ; \quad \forall i, j, k=1,2,3$

Then $p_{i j k}$ is called a Markov chain of order two. Similarly, the Markov chain of order three, four and so on can be defined.

\section{M.L. Estimation of Parameters}

Anderson and Goodman (1957) continued to the development of the statistical inference for Markov chain. Suppose that the states be $\mathrm{j}=1,2,3$ and the time points of observations be $\mathrm{t}=1,2 \ldots \mathrm{T}$. Let $p_{j k}(t),(\mathrm{k}=1,2,3)$ be the probability of state $\mathrm{k}$ at time $\mathrm{t}$, given that the state $\mathrm{j}$ at the time (t-1). If $p_{j k}(t)$ is stationary, then $p_{j k}(t)=p_{j k}$, for all $\mathrm{t}$, otherwise it is non-stationary.

Let us consider a Markov chain with stationary transition probabilities $p_{j k}(\mathrm{j}=1,2,3)$ and a finite number of states $(1$, $2,3)$. Let $n_{j k}$ be the number of observation in the transition from the state $\mathrm{j}$ to the state $\mathrm{k}$.

The total number of observation is $\sum_{j=1}^{3} \sum_{k=1}^{3} n_{j k}$, where, $\mathrm{j}, \mathrm{k}=1,2,3$

$\sum_{k=1}^{3} n_{j k}=n_{j .}$ and $\sum_{j=1}^{3} n_{j k}=n_{. k}$

Whittle (1955) noted that the observation Markov chain model from a set of independent multinational trails. He has obtained the exact probability density of the observed $n_{j k}$

$f\left(n_{i j}\right)=T\left(n_{i j}\right) \frac{\prod_{j}\left(n_{j}\right)}{\prod_{j k}\left(n_{j k}\right) !} \prod_{j k} p_{j k}^{n_{j k}}$

The factor $T\left(n_{j k}\right)$ is the joint probability density of $n_{j}{ }^{\prime} s$ and is independent of $p_{j k}{ }^{\prime} s$. If we consider a Markov chain model with non-stationary transition probabilities $p_{j k}(t)$ then the probability density of $n_{j}(t)$ is given by

$f\left\{n_{j k}(t)\right\}=T\left\{n_{j k}(t)\right\} \frac{\prod_{j}\left\{n_{j .}(t)\right\}}{\prod_{j} \prod_{k}\left\{n_{j k}(t)\right\} !} \prod_{j} \prod_{k} p_{j k}^{n_{j k}}(t)$

In case of non stationary transition probabilities, the set $\sum_{t=1}^{T} n_{j k}=n_{j k}(t)$.

From a set of sufficient statistics and in the case of non stationary transition probabilities $p_{i j k}(t)$. The set $n_{i j k}(t)$ from a multinational set of sufficient statistics.

Medhi (1984) obtained the logarithm of likelihood function for stationary transition probabilities $p_{i j k}$ as,

$$
L\left(p_{j k}\right)=C+\sum_{j=1 k=1}^{3} \sum_{j k} n_{j k} \log p_{j k}
$$

The factors $\mathrm{C}$ contains all terms that are independent of $p_{i j k}$. The maximum likelihood estimates of $p_{i j k}$ are found to be $\hat{p}_{j k}=\frac{n_{j k}}{n_{j}}$

For non-stationary transition probabilities, the maximum likelihood estimates are

$\hat{p}_{j k}(t)=\frac{n_{j k}(t)}{n_{j .}(t)}=\frac{n_{j k}(t)}{n_{j .}(t-1)}$ 
Thus, we may estimate the transition probabilities of Markov model. The M.L estimates for the transition probabilities of daily temperature occurrences for Dhaka and Chittagong stations have been shown in following table.

Table 1: Transition probability matrix for Chittagong station

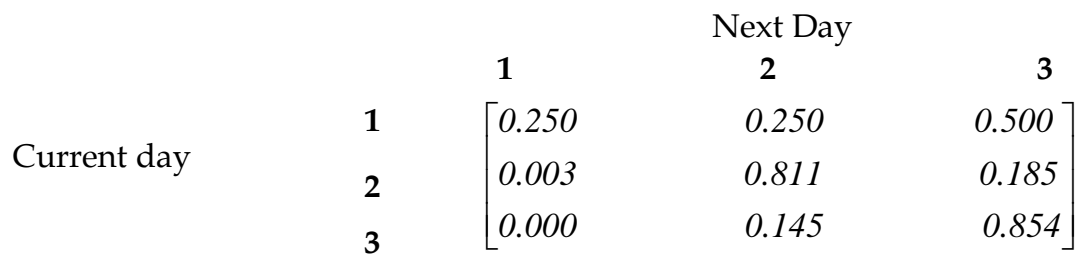

Current day's temperature is high, which will become high temperature in next day that probability is 0.854 . The probability 0.250 indicates that current day temperature is low next day temperature will also be low that probability is 0.250 . The value 0.003 indicates that next day will be low temperature when current day is medium temperature with probability 0.003 . The remaining transition probabilities have been interpreted similarly.

Table 2: Transition probability matrix for Dhaka station

$\left.\begin{array}{clccc}\multicolumn{5}{c}{\text { Next day }} \\ \text { Current day } & 1 & \multicolumn{1}{c}{\begin{array}{c}1 \\ 0.473\end{array}} & 0.368 & 0.157 \\ 0.012 & 0.824 & 0.162 \\ 0.001 & 0.083 & 0.915\end{array}\right]$

The probability 0.473 indicates that current day temperature is low and next day temperature will be low that probability is 0.473 . Current day's temperature is low, which will become high in next day that probability is 0.157 . The value 0.915 means that next day will be high temperature when current day is also high temperature with probability 0.915 . A similar way, all the transition probabilities may be concluded.

\section{Long-Run Behavior of Transition Probabilities}

Feller (1957) developed the unit step,......., m-step transition probabilities by the Chapman and Kolmogorov equation.

The Chapman-Kolmogorov equation is given

$$
p_{j k}^{m+n}=\sum_{i} p_{i k}^{(n)} p_{j i}^{(m)}=\sum_{i} p_{j i}^{(n)} p_{i k}^{(m)}
$$

For all $\mathrm{i}, \mathrm{j}, \mathrm{k}=1,2,3$

Where, $\mathrm{m}$ and $\mathrm{n}$ denote the $\mathrm{mth}$ step and $\mathrm{nth}$ step respectively.

The unit-step transition probabilities denoted by $p_{j k}$ are defined as nth probability of occurrences at the nth probability of occurrence at the nth given occurrence at the (n-1)th step.

The $2^{\text {nd }}$ step transition probabilities $p_{j k}^{(2)}$ are defined as

$$
p_{j k}^{(2)}=\operatorname{prob}\left(x_{n+2}=k / x_{n}=j\right)
$$

Therefore, the mth steps transition probabilities are

$$
p_{j k}^{(m)}=\operatorname{prob}\left(x_{n+m}=k / x_{n}=j\right)
$$

Hence, the Chapman-Kolmogorov equation has been applied to analyze the limiting behavior of daily temperature occurrences for the selected stations, and the results are shown below.

Using the information from Table 1 and Table 2, the steady state distribution of daily temperature after an $\mathrm{n}$ day which is shown in Table 3 considers the initial probabilities $\left[\begin{array}{lll}1 & 0 & 0\end{array}\right]$. 
Table 3: Limiting behavior of daily temperature of Dhaka and Chittagong stations

\begin{tabular}{|c|c|c|c|c|c|c|}
\hline \multirow{3}{*}{ After $n$ days } & \multicolumn{3}{|c|}{ Dhaka Station } & \multicolumn{3}{|c|}{ Chittagong Station } \\
\hline & \multicolumn{3}{|c|}{ Temperature } & \multicolumn{3}{|c|}{ Temperature } \\
\hline & Low & Medium & High & Low & Medium & High \\
\hline Day 0 & 1 & 0 & 0 & 1 & 0 & 0 \\
\hline Day 1 & 0.4730 & 0.3680 & 0.1570 & 0.2500 & 0.2500 & 0.5000 \\
\hline Day 2 & 0.2283 & 0.4903 & 0.2775 & 0.0633 & 0.3378 & 0.5983 \\
\hline Day 3 & 0.1141 & 0.5111 & 0.3692 & 0.0168 & 0.3765 & 0.6050 \\
\hline Day 4 & 0.0605 & 0.4938 & 0.4386 & 0.0053 & 0.3973 & 0.5947 \\
\hline Day 5 & 0.0350 & 0.4655 & 0.4908 & 0.0025 & 0.4097 & 0.5841 \\
\hline Day 6 & 0.0226 & 0.4372 & 0.5300 & 0.0019 & 0.4176 & 0.5759 \\
\hline Day 7 & 0.0165 & 0.4126 & 0.5593 & 0.0017 & 0.4227 & 0.5700 \\
\hline Day 8 & 0.0133 & 0.3924 & 0.5812 & 0.0017 & 0.4259 & 0.5658 \\
\hline Day 9 & 0.0116 & 0.3765 & 0.5974 & 0.0017 & 0.4278 & 0.5628 \\
\hline Day 10 & 0.0106 & 0.3641 & 0.6095 & 0.0017 & 0.4290 & 0.5607 \\
\hline Day 11 & 0.0100 & 0.3545 & 0.6183 & 0.0017 & 0.4296 & 0.5590 \\
\hline Day 12 & 0.0096 & 0.3471 & 0.6248 & 0.0017 & 0.4300 & 0.5583 \\
\hline Day 13 & 0.0093 & 0.3414 & 0.6294 & 0.0017 & 0.4300 & 0.5583 \\
\hline Day 14 & 0.0091 & 0.3370 & 0.6327 & & & \\
\hline Day 15 & 0.0090 & 0.3335 & 0.6349 & & & \\
\hline Day 16 & 0.0089 & 0.3309 & 0.6364 & & & \\
\hline Day 17 & 0.0088 & 0.3287 & 0.6373 & & & \\
\hline Day 18 & 0.0088 & 0.3270 & 0.6378 & & & \\
\hline Day 19 & 0.0087 & 0.3256 & 0.6379 & & & \\
\hline Day 20 & 0.0087 & 0.3244 & 0.6378 & & & \\
\hline Day 21 & 0.0086 & 0.3235 & 0.6375 & & & \\
\hline Day 22 & 0.0086 & 0.3226 & 0.6371 & & & \\
\hline Day 23 & 0.0086 & 0.3219 & 0.6365 & & & \\
\hline Day 24 & 0.0086 & 0.3212 & 0.6359 & & & \\
\hline Day 25 & 0.0085 & 0.3206 & 0.6709 & & & \\
\hline Day 26 & 0.0085 & 0.3206 & 0.6709 & & & \\
\hline
\end{tabular}

Long-run distributions have not been affected by initial probabilities (Mahanta et al., 2016). After 26 (since day 0 represents the first day) days the distribution will be stationary have been shown in Table 3. There is no impact of temperature after 26 days in Dhaka station. In future, in a certain day temperature will be high, medium and low with probability $0.67,0.32$ and 0.01 respectively. Table 2 represent that current day's temperature is high and next day will be high that probability is 0.915 . That means the temperature of Dhaka is increasing day-by-day, which is alarming for us.

Again, in Chittagong station, stationary probability occurred after 13 (since day 0 represents the first day) days. That means there is no impact between current days temperature with after 13 days temperature. In future, on a specific day $56 \%$, $43 \%$, and rest temperature will be high, medium and low respectively. From the table 1 current day is high temperature will be high in next day that probability is 0.854 that means the temperature of Chittagong day by day increasing.

\section{TEST FOR MARKOV MODEL}

The maximum likelihood estimate of the transition probability has been used to test whether the daily temperature occurrences are independent or not. To perform this test the null hypothesis that the successive observation for daily temperature are statistically independent against the alternative that the daily temperature occurrences follow the Markov chain of order one has been considered, i.e.

$H_{0}: P_{j k}=p_{k}$ against $H_{1}: P_{j k} \neq p_{k}$

Using the likelihood ratio criterion Anderson and Goodman (1957) have shown that

$\chi^{2}=2 \sum_{j=1 k=1}^{3} \sum_{k=1}^{3} n_{j k} \log \left\{\frac{n_{j k} \times N}{n_{j .} \times n_{. k}}\right\}$

where $n_{j k}$ is the transition count for $j^{t h}$ and $k^{t h}$ cell, $n_{. k}$ is $\sum_{j=1}^{3} n_{j k}$ and $n_{. j}$ is $\sum_{k=1}^{3} n_{j k}$.

Both Chittagong and Dhaka station the above $\chi^{2}$ statistic has been applied for testing the null hypothesis that temperature occurrence follows Markov model. The degrees of freedom of $\chi^{2}$ statistic is $\left(r^{q}-1\right)(c-1)$. Where $r$ is the number of rows, $c$ is the number of columns and $q$ is the order of Markov model.

Observed value of $\chi^{2}$ statistic for corresponding null hypothesis and degrees of freedom have been presented in table 4 . 
Table 4: Observed value of $\chi^{2}$ for null hypotheses of Chittagong station

\begin{tabular}{|c|c|c|}
\hline Null hypothesis & $\begin{array}{l}\text { Observed Value of } \\
\qquad \chi^{2}\end{array}$ & $\begin{array}{l}\text { Degrees of freedom, } \\
\quad\left(r^{q}-1\right)(c-1)\end{array}$ \\
\hline $\begin{array}{l}H_{01}: P_{j k}=p_{1} \\
\text { i.e. Stationary distribution follows } 1^{\text {st }} \text { order Markov chain. }\end{array}$ & $498.66^{* * *}$ & 4 \\
\hline $\begin{array}{l}H_{02}: P_{j k}=p_{2} \\
\text { i.e. Stationary distribution follows } 2^{\text {nd }} \text { order Markov chain. }\end{array}$ & $360.90^{* * *}$ & 16 \\
\hline $\begin{array}{l}H_{03}: P_{j k}=p_{3} \\
\text { i.e. Stationary distribution follows } 3^{\text {rd }} \text { order Markov chain. }\end{array}$ & $290.63^{* * *}$ & 52 \\
\hline $\begin{array}{l}H_{05}: P_{j k}=p_{5} \\
\text { i.e. Stationary distribution follows } 5^{\text {th }} \text { order Markov chain. }\end{array}$ & 232.57 & 484 \\
\hline $\begin{array}{l}H_{010}: P_{j k}=p_{10} \\
\text { i.e. Stationary distribution follows } 10^{\text {th }} \text { order Markov chain. }\end{array}$ & 204.89 & 118096 \\
\hline 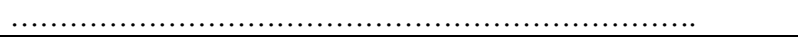 & ................... & 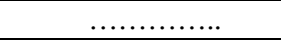 \\
\hline $\begin{array}{l}H_{013}: P_{j k}=p_{13} \\
\text { i.e. Stationary distribution follows } 13^{\text {th }} \text { order Markov chain. }\end{array}$ & 153.83 & 3188644 \\
\hline
\end{tabular}

*** Significant at 0.001 level, ${ }^{* *}$ Significant at 0.01 level

The table shows that the observed value of Chittagong station $\chi^{2}$ is found to be 498.66 for first order Markov chain, and which is highly significant at 0.001 levels with 4 degrees of freedom. Therefore, based on this test we may say that the daily temperature occurrences don't follow $1^{\text {st }}$ order Markov chain for Chittagong.

Then, the observed value of Chittagong station $\chi^{2}$ is found to be 360.90 for second order Markov chain, and which is significant at 0.001 levels with 16 degrees of freedom. Therefore, based on this test we may say that the daily temperature occurrences don't follow second order Markov chain for Chittagong.

Also, the observed value of Chittagong station $\chi^{2}$ is found to be 290.63 for third order Markov chain, and which is at 0.001 levels of significance with 52 degrees of freedom. Therefore, based on this test we may say that the daily temperature occurrences don't follow third order Markov chain for Chittagong.

Furthermore, the observed value of Chittagong station $\chi^{2}$ is found to be 232.57 for $5^{\text {th }}$ order Markov chain, and which is not significant at levels with 484 degrees of freedom. Therefore, based on this test we may say that the daily temperature occurrences follow $5^{\text {th }}$ order Markov chain for Chittagong.

From table finally, it is notable that, the daily temperature of Chittagong station occurrences is not specified by first, second or third orders Markov chain. Here we can observe that the daily temperature of Chittagong station follows $5^{\text {th }}$ order Markov chain. However, test for independence showed that daily temperature occurrences follow a Markov chain of $5^{\text {th }}$ order. That means after five days impact of temperature will be nil. Hence we proceed to measure the strength of association to specify whether the daily temperature occurrences follow a Markov chain of order 13.

Observed value of $\chi^{2}$ for corresponding null hypothesis has been shown in Table 5.

The observed value of $\chi^{2}$ for Dhaka station have been observed to be $1172.80,943.95,829.72$ and 711.44 for $1^{\text {st }}$ order, $2^{\text {nd }}$ order, $3^{\text {rd }}$ order and $5^{\text {th }}$ order Markov chain respectively, and in case of $1^{\text {st }}$ order and $2^{\text {nd }}$ order Markov chain the value of $\chi^{2}$ is highly significant at $1 \%$ level of significance with their respective degrees of freedom. Therefore, based on this test we can draw a conclusion that the daily temperature occurrences don't follow $1^{\text {st }}$ order $2^{\text {nd }}$ order, $3^{\text {rd }}$ order and $5^{\text {th }}$ order Markov chain for Dhaka. But temperature occurrences follow $10^{\text {th }}$ order Markov chain. That means after ten days, there is no impact of temperature in Dhaka.

Hence we proceed to measure the strength of association to specify whether the daily temperature occurrences of Dhaka station follow a Markov chain of $26^{\text {th }}$ order. 
Table 5: Observed value of $\chi^{2}$ for null hypotheses of Dhaka station

\begin{tabular}{|c|c|c|}
\hline Null hypothesis & $\begin{array}{l}\text { Observed Value of } \\
\qquad \chi^{2}\end{array}$ & $\begin{array}{l}\text { Degrees of freedom, } \\
\quad\left(r^{q}-1\right)(c-1)\end{array}$ \\
\hline $\begin{array}{l}H_{01}: P_{j k}=p_{1} \\
\text { i.e. Stationary distribution follows } 1^{\text {st }} \text { order Markov chain. }\end{array}$ & $1172.80^{* * *}$ & 4 \\
\hline $\begin{array}{l}H_{02}: P_{j k}=p_{2} \\
\text { i.e. Stationary distribution follows } 2^{\text {nd }} \text { order Markov chain. }\end{array}$ & $943.95^{* * *}$ & 16 \\
\hline $\begin{array}{l}H_{03}: P_{j k}=p_{3} \\
\text { i.e. Stationary distribution follows } 3^{\text {rd }} \text { order Markov chain. }\end{array}$ & $829.72^{* * *}$ & 52 \\
\hline $\begin{array}{l}H_{05}: P_{j k}=p_{5} \\
\text { i.e. Stationary distribution follows } 5^{\text {th }} \text { order Markov chain. }\end{array}$ & $711.44^{* * *}$ & 484 \\
\hline $\begin{array}{l}H_{010}: P_{j k}=p_{10} \\
\text { i.e. Stationary distribution follows } 10^{\text {th }} \text { order Markov chain. }\end{array}$ & 632.94 & 118096 \\
\hline $\begin{array}{l}H_{015}: P_{j k}=p_{15} \\
\text { i.e. Stationary distribution follow s } 15^{\text {th }} \text { order Markov chain. }\end{array}$ & 578.55 & 28697812 \\
\hline 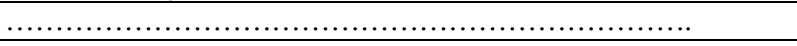 & f.................. & f........... \\
\hline $\begin{array}{l}H_{026}: P_{j k}=p_{26} \\
\text { i.e. Stationary distribution follows } 26^{\text {th }} \text { order Markov chain. }\end{array}$ & 388.14 & $5083731657 \times 10^{3}$ \\
\hline
\end{tabular}

Sinha and Paul (1992) applied $V^{2}$ for measuring the strength of association. Cramer (1946) has suggested a measurement denoted by $V^{2}$ for measuring the strength of association. This measurement $V^{2}$ is defined as $V^{2}=\frac{\chi^{2} / n}{\min \left(r^{q}-1, c-1\right)}$.

Where $\mathrm{r}$ is the number of rows, $\mathrm{c}$ is the number of and columns and $\mathrm{n}$ is the total number of observations. This measurement is called Cramer's $V^{2}$, falls between 0 and 1 with large values representing stronger association and it is identical to the square of Pearsonian correlation coefficient. The measurement has been employed for measuring the strength of association among the daily temperature occurrences. The values of $V^{2}$ and corresponding correlation coefficient are shown in Table 6 and Table 7.

Table 6: Observed values of $V^{2}$ and coefficient of correlation for different order Markov chain (Chittagong station).

\begin{tabular}{ccc}
\hline Markov chain & Observed values of $V^{2}$ & Coefficient of correlation $r$ \\
\hline $1^{\text {st }}$ order & 0.1138 & 0.3373 \\
\hline $2^{\text {nd }}$ order & 0.0824 & 0.2871 \\
\hline $3^{\text {rd }}$ order & 0.0665 & 0.2579 \\
\hline $5^{\text {th }}$ order & 0.0532 & 0.2307 \\
\hline $10^{\text {th }}$ order & 0.0470 & 0.2168 \\
\hline$\ldots \ldots \ldots \ldots \ldots \ldots \ldots \ldots \ldots \ldots \ldots \ldots \ldots \ldots \ldots \ldots \ldots \ldots \ldots \ldots \ldots \ldots \ldots \ldots \ldots \ldots \ldots \ldots \ldots \ldots \ldots \ldots \ldots \ldots$ \\
\hline $13^{\text {th }}$ order & 0.0353 & $0.1879 \ldots \ldots$ \\
\hline
\end{tabular}

The table depicts that the association decreases when the order increases for Chittagong station. In $1^{\text {st }}$ order, the coefficient of correlation is 0.3373 and in $13^{\text {th }}$ order which is 0.1879 . That is the impact of temperature decreases when order increases.

Table 7: Observed values of $V^{2}$ and coefficient of correlation for different order Markov chain (Dhaka station).

\begin{tabular}{|c|c|c|}
\hline Markov chain & Observed values of $V^{2}$ & Coefficient of correlation 1 \\
\hline $1^{\text {st }}$ order & 0.1460 & 0.3821 \\
\hline $2^{\text {nd }}$ order & 0.1175 & 0.3428 \\
\hline $3^{\text {rd }}$ order & 0.1033 & 0.3214 \\
\hline $5^{\text {th }}$ order & 0.0886 & 0.2977 \\
\hline $10^{\text {th }}$ order & 0.0790 & 0.2811 \\
\hline $15^{\text {th }}$ order & 0.0723 & 0.2689 \\
\hline .............. & .................. & $\ldots \ldots \ldots \ldots \ldots \ldots \ldots \ldots$ \\
\hline $26^{\text {th }}$ order & 0.0486 & 0.2205 \\
\hline
\end{tabular}


The table 7 represents that the association decreases when the order increases and the coefficient of correlation 0.3821 with Observed values of $V^{2}$ is 0.1460 for $1^{\text {st }}$ order. The above results represent that strength of association decreases on its order.

\section{CONCLUSIONS}

The climate change has been escalating over the centuries, causing a complete upturned impact of the ecosystem of the earth surface. The historical climate change along with the present rate of change has influenced us to project the further climate change. Because of climate change, will increase evaporate transpiration and create situations like water loss from soil, resultantly reduced crop yield, and lower level of water both in surface and ground water systems, higher microbial concentration, and growth rate in the surface waters and so on. If not checked in time, the exacerbating aridity and accompanying desertification process as consequence of increased surface temperature is destined to cause severe environmental degradation in different part of the country.

This paper analyzes the temperature data of two stations such as Chittagong and Dhaka to predict the overall condition of temperature in future. Then we have analyzed the Markov chain model for the long-term behavior of temperature for two different stations. About $67.09 \%$ and 55.83\% temperature will be high in Dhaka and Chittagong stations respectively have been observed. Using Cramer $V^{2}$, the strength of association has been measured and increasing the order of Markov chain decreases its strength.

Bangladesh should also prepare adaptation policies to minimize the adverse effect of climate change. Vulnerabilities assessment, disaster management, enhanced structure design, institutional reform and anti-extreme climate engineering are some feasible adaptation policies in Bangladesh due to increasing temperature.

\section{REFERENCES}

Anderson, T. W., \& Goodman, L. A. (1957). Statistical inference about Markov chains. The Annals Mathematical Statistics , 89-110.

Chan, J. C. (2006). Comments on "Changes in tropical cyclone number, duration and intensity in a warming environment. Science , $311,1713$.

Feller, W. (1957). An introduction to probability theory and its applications (2nd ed., Vol. 2). New York: John Wiley \& Sons.

Gabriel, K. R. \& Neumann, J. (1962). A Markov chain model for daily rainfall occurrence at Tel Aviv, Quarterly Journal of Royal Meteorological Society. 83, 90-95.

Haque, M. Z., Quayyam, H. A., Hossian, M. M., \& Islam, M.S. (1992) Occurrence of grain sterility in different rice crops. Bangladesh Bureau of Statistics (BBS), 117-124.

Harmeling, S. (2008). Weather-related loss and Their Impacts on Countries in 2007 and in a Long Term Comparison. 5-8.

IUCN, Bangladesh (2011). Protocol for Monitoring of Impacts of Climate Change and Climate Variability in Bangladesh. Dhaka, Bangladesh.

Karim, Z. (1993). Preliminary Agricultural Vulnerability Assessment: Drought Impacts due to Climate Change in Bangladesh. IPCC Eastern Hemisphere Workshop on Vulnerability Assessment to Sea-Level Rise and Coastal Zone Management.

Mahanta, J., Nath, S. K., \& Rashid, M. H. (2016). Using Markov analysis to study the impact of temperature in Bangladesh. Asia Pacific Journal of Energy Environment , 3 (3), 105-112.

Medhi, J. (1984). Stochastic Process. New age international publishers.

Peterson, T. C., X.Zhang, M. B., \& Aguirre, J. L. (2008). Changes in North American extremes derived from daily weather data. J. Geophys. Res , 113.

Rosenberg, S., Vedlitz, A., Cowman, D., \& Zahran, S. (2010). Climate change: a profile of U.S. climate scientists perspective. Clim Chang , $101(3-4), 663-668$.

Sahney, S., Benton, M. J., \& Ferry, P. (n.d.). "Link between global taxonomic diversity, ecological diversity and the expansion of vertebrates on land". Biology Letters .

Sinha, N. C., \& Paul, J. C. (1992). Analysis of daily rainfall occurrance for Sylhet Station: An application of Markov model. Bangladesh J. Sci. Res , 10 (1), 95-102.

Stern, R. D. \& Coe, R. (1984). A model fitting analysis of daily rainfall data, Journal of Royal Statistical Society, Ser. A. 147, 1-34.

Whittle, P. (1955). Some distribution and moment formulae for the Markov chain. Journal of Royal Statistical Society , $235-242$.

World Bank (2000). Bangladesh: Climate Change \& Sustainable Development. Report No. 21104. Dhaka, Bangladesh.

$$
--0 \text {-- }
$$

